\title{
Mediações pedagógicas com alunos com deficiência e necessidade complexa de comunicação: percepção dos professores
}

Pedagogical mediations with non-speaking students: teachers' perception

Mediaciones pedagógicas con alumnos con discapacidad y necesidad compleja de comunicación: percepción de los profesores

\author{
Vanessa Calciolari Rigoletti \\ Doutoranda na Universidade Estadual Paulista Júlio Mesquita Filho, Marília, São Paulo, Brasil. \\ vanessarigoletti@hotmail.com \\ ORCID - https://orcid.org/0000-0002-6188-1070
}

Débora Deliberato

Professora doutora na Universidade Estadual Paulista Júlio Mesquita Filho, Marília, São Paulo, Brasil. debora.deliberato@unesp.br

ORCID - https://orcid.org/0000-0003-4756-042X

Recebido em 2 de maio 2019

Aprovado em 9 de abril de 2020

Publicado em 27 de maio de 2020

\section{RESUMO}

Com a inclusão escolar de todos os alunos no ensino regular, discute-se como o professor promove a sua rotina direcionada aos alunos com necessidades específicas. Parte de um estudo abrangente, este artigo teve como objetivo identificar as mediações dos professores direcionadas ao aluno com deficiência e necessidade complexa de comunicação. Participaram dez professores do ensino regular de $1^{\circ}$ ao $5^{\circ}$ ano. Os instrumentos utilizados foram a entrevista semiestruturada e o Protocolo de Habilidades Comunicativas. Os dados foram transcritos e analisados de acordo com o objetivo proposto. Estabeleceram-se temas e subtemas. Dentre eles, destacou-se o Tema Rotina Pedagógica da Sala de Aula, como parte o subtema Mediação do Professor, no qual este estudo se direcionou. Os resultados evidenciaram que o aluno com necessidade complexa de comunicação traz desafios para os professores em sua proposta de mediação. Tais dados sugerem discussões que possam contribuir não somente com as mediações realizadas pelo professor, mas de forma que suas inquietações promovam buscas sólidas na rotina escolar, com objetivos claros no desenvolvimento do conhecimento dos alunos. Conclui-se que os professores precisam traçar um plano de mediação pedagógica que possa contribuir com as aprendizagens de tais alunos. Este estudo indicou relevância no direcionamento do professor do ensino regular quanto ao planejamento das mediações pedagógicas, a fim de eliminar barreiras que possam interferir na rotina pedagógica da sala de aula, na comunicação e na aprendizagem do aluno com deficiência e necessidade complexa de comunicação.

Palavras-chave: Educação Especial; mediação pedagógica; comunicação alternativa. 
http://dx.doi.org/10.5902/1984686X37968

\section{ABSTRACT}

The inclusion of all students in the regular education creates the discussion: how can teachers promote their routine? This article is part of a larger study, and its aim is to identify how teachers interact with students who have non-speaking disability. Ten regular teachers, from 1st to 5th year, participated in the study. As instruments of research, the semistructured interview and the Protocolo de Habilidades Comunicativas (Communicative Skills Protocol) were used. The data were transcribed and analyzed, according to the proposed objective. Themes and sub-themes were established. Among them, the subtheme Pedagogical routine in the classroom, was the main subject of the study. This subtheme was part of the theme Mediation of the teacher, to which this study was directed. The results showed that the communication abilities presented by the non-speaking student brings challenges to teachers in their mediation proposal. Such data suggest discussions that can contribute not only to the mediations carried out by the teacher, but can also promote solid researches in the school routine, in order to have clear objectives in the development of students' knowledge. This study concluded that teachers need to develop a pedagogical mediation plan that can contribute to the learning of such students. It indicated that the planning of the pedagogical mediation by teachers of the regular education is important to eliminate barriers that can interfere in the pedagogical routine of the classroom, in the communication and in the education of the student with non-speaking students.

Keywords: Special Education; pedagogical mediation; augmentative and alternative communication.

\section{RESUMEN}

Con la inclusión escolar de todos los alumnos en la enseñanza regular, se discute cómo el profesor promueve su rutina. Este artículo forma parte de un estudio exhaustivo, que tuvo como objetivo identificar las mediaciones de los profesores dirigidas al alumno con discapacidad y necesidad compleja de comunicación. Participaron diez profesores de enseñanza regular de $1^{\circ}$ al $5^{\circ}$ año. Los instrumentos utilizados fueron la entrevista semiestructurada y el Protocolo de Habilidades Comunicativas. Los datos fueron transcritos y analizados, de acuerdo con el objetivo propuesto. Se establecieron temas y subtemas. De entre ellos, se destacó el tema Rutina Pedagógica de la Sala de Clase, como parte del subtema Mediación del Profesor. Los resultados evidenciaron que la condición de comunicación presentada por el alumno con necesidad compleja de comunicación se suman desafíos a los profesores en su propuesta de mediación. Tales datos sugieren discusiones de modo que puedan contribuir no sólo con las mediaciones realizadas por el profesor, sino que sus inquietudes promuevan búsquedas sólidas para la rutina escolar con objetivos claros en el desarrollo del conocimiento de los alumnos. Se concluye que los profesores necesitan trazar un plan de mediación pedagógica que pueda contribuir a los aprendizajes de tales alumnos. Este estudio indicó relevancia en el direccionamiento del profesor de la enseñanza regular, en cuanto a la planificación de las mediaciónes pedagógicas, con la finalidad de eliminar barreras que puedan interferir en la rutina pedagógica del aula, en la comunicación y en el aprendizaje del alumno con discapacidad no hablante.

Palabras clave: Educación Especial; mediación pedagógica; comunicación alternativa. 
http://dx.doi.org/10.5902/1984686X37968

\section{Introdução}

O professor, com sua mediação pedagógica, oportuniza ao aluno a vivência, em ambiente escolar, de diversas relações favoráveis ao desenvolvimento cognitivo, comunicativo e afetivo. O termo "mediação pedagógica" refere-se ao ato do professor intermediar e provocar mudanças no conhecimento acadêmico do aluno. Feuerstein, Klein, Tannenbaum (1994) destacaram que o mediador é o ser que organiza, planeja, promove e dá significados culturais, entre outros, ao mediado.

Magalhães e Mendonça (2016) afirmaram que a aprendizagem na escola acontece por meio da mediação representada por várias intersecções e experiências. Desta forma, entende-se que a mediação pedagógica acontece na rotina escolar, compreendida como a sequência de atividades e de afazeres escolares organizados pelo professor para concretizar suas intenções educativas.

Segundo Reis et al. (2011), a rotina escolar elaborada pelo professor contribui para aproveitamento do tempo e dos conteúdos a serem trabalhados, além de orientar suas ações. De acordo com Bulgraen (2010), o professor, enquanto mediador, deve atuar como ponte entre o aluno e o conhecimento, tendo o dever de intermediar e provocar mudanças nas diversas habilidades acadêmicas.

Embora a literatura aponte a mediação pedagógica como estratégia de intervenção no desenvolvimento do aluno, Mello (2000) destacou as fragilidades no processo de formação do docente que está à frente do ensino fundamental I ( $1^{\circ}$ a $5^{\circ}$ ano) e sublinhou que para a aprendizagem escolar se caracterizar como experiência relevante é indispensável a mediação de professores com conhecimentos de ensino eficazes. A questão é que nem sempre o professor apresenta formação específica e/ou necessária para organizar sua rotina e promover avanços no conhecimento de todos os seus alunos por meio da mediação pedagógica (RIGOLETTI, 2018).

Schirmer (2013) em suas pesquisas sobre a formação inicial de professores, destacou que os dados indicam que no processo de formação as necessidades e as exigências dos professores devem ser consideradas; suas concepções, metodologias e conhecimentos prévios sobre os temas a serem propostos devem ser identificados.

Dudas (2013) ao analisar relatos de professores do ensino regular (Fundamental I) pontuou as dificuldades e os desafios dos professores em desenvolver suas atribuições após sua formação. Segundo Gasparin (2007), o professor necessita assumir seu papel 
http://dx.doi.org/10.5902/1984686X37968

frente às mediações pedagógicas, passando a ser o provocador, mediador, facilitador e orientador da aprendizagem.

A opinião é compartilhada por Cardoso e Toscano (2011), ao enfatizarem a importância da mediação pedagógica na aprendizagem, apontando que o professor precisa de embasamento teórico para propor desafios satisfatórios em direção ao desenvolvimento de cada um.

Outra questão que se discute é o distanciamento do que é proposto ao aluno na rotina escolar e a real necessidade de cada um. Libâneo (1994) explicou que o professor como mediador precisa colocar os alunos em situações que partam de suas necessidades e estimulem seu interesse.

Entre o público encontrado na escola, espera-se que crescentemente alunos com necessidades educacionais específicas possam estar inseridos em sala regular de ensino. Sabe-se que, desta maneira, o professor deverá considerar as diversas características que compõem o quadro dos alunos com deficiência, habilidades diversas e transtorno do espectro do autismo.

A necessidade complexa de comunicação, ausência ou insuficiência da fala poderá estar presente dentre as características de tais alunos e representar uma das barreiras encontradas nas mediações pedagógicas. Silva e Deliberato (2003) discutiram as dificuldades e preocupações dos professores em organizar seus trabalhos com os alunos com deficiência e necessidade complexa de comunicação. Para esta condição, Moreschi e Almeida (2017) alertaram que o ponto inicial da ação do professor é reconhecer outras formas de comunicação que vão além da fala.

A voz do aluno representada por outros meios e suportes favorece a comunicação entre o professor, aluno e parceiros e possibilita as mediações pedagógicas. Sobrinho e Medrado (2017) explicaram em seus estudos que a comunicação pode se apresentar de diversas formas e o uso delas em contexto escolar favorece as ações do professor.

Ao se referir às mediações pedagógicas direcionadas ao aluno com deficiência, Carneiro (2006) alertou que o professor necessita de processos mais qualificados se comparados ao direcionamento de suas ações com o aluno sem deficiência. Por processos mais qualificados pode-se entender uma formação mais específica que contemple o conhecimento das condições do aluno, a fim de propor uma rotina pedagógica que oportunize o desenvolvimento e a aprendizagem de habilidades acadêmicas. 
http://dx.doi.org/10.5902/1984686X37968

Deste modo, o presente estudo aponta aspectos relevantes para o direcionamento do professor do ensino regular quanto ao manejo e reflexões de suas mediações, de forma a contribuir com o direito do aluno com deficiência e necessidade complexa de comunicação a participar de uma rotina pedagógica permeada por comunicação e aprendizagem.

Este estudo parte de um projeto abrangente, denominado "Formação de Professores no Contexto da Comunicação Alternativa", que apresentou como objetivos capacitar os professores no contexto da Comunicação Suplementar e Alternativa e sistematizar o conteúdo necessário para cursos de formação de professores quanto ao uso de recursos de tecnologia assistiva envolvendo linguagens alternativas na escola.

A vertente deste estudo teve como base a dissertação de mestrado de Rigoletti (2018), a qual, como citado, integrou pesquisa maior submetida à avaliação pelo Comitê de Ética em Pesquisa (CEP) vinculado à Faculdade de Filosofia e Ciências da Unesp de Marília, respeitando as prerrogativas da resolução 466/2012 do CONEP, que versa sobre ética em pesquisa com seres humanos, sob o $n^{\circ} 55431216.6 .00005406$. Parecer favorável ao $n^{\circ}$ 1.525.070.

De acordo com os estudos de Rigoletti (2018), o professor é indispensável na promoção do desenvolvimento acadêmico do aluno com deficiência e necessidade complexa de comunicação, e sua mediação pedagógica determina grande parte do avanço no desenvolvimento escolar.

O uso de recurso (jogos, alfabeto móvel, figuras de comunicação, kits, livros, computador, objetos e materiais diversos, etc...) é um aliado potente ao trabalho do professor para que possa apoiar sua finalidade pedagógica. Manzini e Deliberato (2007) definiram "recurso" como um estímulo concreto que pode ser manipulável e atribuído ao objetivo com o aluno. Reganhan (2006) afirmou que o trabalho pedagógico requer o uso de recursos, sendo estes adaptados, quando necessário, de modo a possibilitar ao aluno a aprendizagem.

Rigoletti (2018) evidenciou a dificuldade dos professores munirem os alunos com deficiência e necessidade complexa de comunicação com recursos que possibilitem sua atuação na rotina escolar.

Nas escolas é comum observar que alunos com deficiência sem a condição de falantes poucas vezes assumem papel ativo na rotina, ou seja, pouco iniciam uma situação de interlocutor. Dudas (2013) se preocupou em destacar que a ausência de recursos e instrumentos facilitadores no processo escolar do aluno pode contribuir para o seu papel de observador. 
http://dx.doi.org/10.5902/1984686X37968

Nesta direção, a promoção de mediações pedagógicas que atendam as especificidades do aluno com necessidade complexa de comunicação favorece uma retomada de papéis e suas dificuldades cedem espaço à exposição de habilidades acadêmicas que o aluno possa ter ou venha a adquirir.

Fabri e Sella (2017) alertaram o quanto a retomada de papéis pode favorecer a exposição do potencial do aluno com deficiência e necessidade complexa de comunicação, possibilitando que não seja identificado apenas por suas limitações.

Vale destacar que o aluno com deficiência deve ter participação plena no ambiente escolar, ou seja, em todas as atividades pedagógicas (GUERREIRO, 2012). Entre as responsabilidades do professor está o dever de desenvolver, com excelência, seu trabalho pedagógico de modo a contemplar a inclusão (BRASIL, 2015).

Incluir todos no ensino regular e promover um ensino que atenda as diversidades são princípios previstos nas políticas públicas, como a Lei Brasileira de Inclusão, LBI n 13.146 (BRASIL, 2015), que reconhece a responsabilidade do trabalho pedagógico no processo do desenvolvimento das potencialidades do aluno e sua inclusão escolar.

A LBI n 13.146, homologada em 06 de julho de 2015, reafirma o direito dos alunos com deficiências a frequentarem o ensino regular ministrado por professor sem formação específica obrigatória para lidar com a necessidade de cada aluno e desenvolver trabalho pedagógico que contemple a inclusão de todos (BRASIL, 2015).

O professor deve garantir ao público da Educação Especial a abertura de um caminho que possibilite o aperfeiçoamento de sua comunicação, além de proporcionar o apoio nas suas necessidades de relação e comunicação com o entorno escolar e na realização de atividades de sua rotina pedagógica.

Herculiani e Deliberato (2010) pontuaram que os alunos com deficiência e necessidade complexa de comunicação têm encontrado ajuda nos recursos que apoiam e favorecem a comunicação. São exemplos desses recursos as pranchas de comunicação, fichas contendo imagens associadas aos conteúdos, livros temáticos, agendas para registros e apoio da linguagem expressiva, fotos, entre outros.

Massaro e Deliberato (2013) afirmaram que se faz necessário o conhecimento dos recursos que os alunos precisam para realizar as atividades e destacaram que identificar as habilidades específicas de cada aluno é um cuidado fundamental para a implementação de fato dos recursos alternativos e suplementares de comunicação. 
http://dx.doi.org/10.5902/1984686X37968

Aponta-se assim, a necessidade de um trabalho pedagógico por meio de mediações pedagógicas representadas por caminhos alternativos que possam dar suporte à ausência ou insuficiência de fala e trazer benefícios ao aluno, como a implementação e o uso da Comunicação Suplementar Alternativa (CSA) em ambiente escolar.

De acordo com a American Speech-Language-Hearing Association-ASHA (1989) a CSA é uma área de atuação clínica e educacional que objetiva compensar, de modo temporário ou permanente, dificuldades de indivíduos com distúrbios severos de expressão, ou seja, prejuízos severos de fala, linguagem e escrita.

Deste modo, a CSA inclui o uso de olhares, expressões, gestos, toques, escrita, apontar de símbolos, figuras, imagens, dentre outros meios que permitem a comunicação entre o indivíduo com fala insuficiente ou ausente e seu interlocutor (MONNERAT; WALTER, 2017).

Em ambiente escolar, Massaro e Deliberato (2013) explicitaram que muitos são os benefícios do uso da CSA em favor da aprendizagem. Donati (2017) destacou que, entre os benefícios, encontra-se o acesso ao pensamento do outro e a possibilidade da expressão de si mesmo.

Moreschi e Almeida (2017) discutiram que as possibilidades diversas de comunicação devem ser compartilhadas com os colegas, de forma que os parceiros de comunicação compreendam o modo e o meio que favorecem a comunicação do aluno com necessidade complexa de comunicação.

Schirmer (2011) explicou que estes parceiros precisam estar interessados e ter competência para interagir e se comunicar com usuários de CSA, ao passo que Deliberato (2017) pontuou que em sua maioria as escolas não apresentam interlocutores competentes em utilizar os recursos e estratégias da CSA em suas atividades pedagógicas.

O acesso de todos ao ensino regular, garantido por lei, justifica a importância de estudos para identificar como o professor planeja sua mediação pedagógica, a fim de eliminar barreiras que possam interferir na rotina da sala de aula, na comunicação e na aprendizagem do aluno com deficiência e necessidade complexa de comunicação.

Ao se considerar a relevância da temática é que se destacou neste estudo o objetivo de identificar as percepções dos professores quanto as suas mediações pedagógicas direcionadas ao aluno com deficiência e necessidade complexa de comunicação. 
http://dx.doi.org/10.5902/1984686X37968

\section{Método}

A pesquisa tomou como base a necessidade de identificar as percepções dos professores do ensino fundamental I quanto a sua mediação pedagógica, desta forma primou-se por um método de natureza descritiva qualitativa que buscasse identificar e descrever os fatos e os fenômenos de determinada realidade (TRIVIÑOS, 1987).

Fiorin (1998) pontuou que os significados estão diretamente relacionados às formações discursivas existentes na sociedade, em que podem ser interpretados por uma diversidade de olhares.

Os procedimentos sistemáticos para a descrição e a explicação de fenômenos, priorizou a etapa dos procedimentos de seleção dos participantes, instrumentos utilizados, procedimentos para coleta e análise de dados, fundamentados nas teorias existentes.

\section{Procedimentos de seleção dos participantes}

Este estudo primou por selecionar como participantes professores do ensino regular Fundamental I ( $1^{\circ}$ ao $5^{\circ}$ ano) de escola pública e privada. Foram selecionados dez professores com idades entre 25 a 41 anos, que apresentavam em suas salas de aula discentes com deficiência e necessidade complexa de comunicação.

Para a seleção dos participantes foram realizados os seguintes procedimentos:

a) Autorização para a realização do projeto de pesquisa emitida pela Secretaria de Educação de um município do interior de São Paulo e Secretaria da Rede Particular de Ensino do mesmo município, mediante o envio de ofício e cópia do projeto de pesquisa maior ao qual esse trabalho está integrado;

b) Após a autorização das Secretarias para a realização da pesquisa, a rede Municipal solicitou à Secretaria da Educação Especial Municipal que indicasse quais escolas apresentavam discentes com deficiência e necessidade complexa de comunicação e quais professores do ensino regular fundamental I atendiam estes alunos. No caso da Rede Particular foram solicitados à direção da escola os nomes dos professores que atendiam alunos com deficiência e com necessidade complexa de comunicação;

c) Em sequência, foi realizado contato com os diretores, solicitando que autorizassem os professores a participar do estudo;

d) Após o aval dos diretores, a pesquisadora entrou em contato com os professores para esclarecimentos a respeito da pesquisa, explanando seus objetivos e seu funcionamento. Os 
http://dx.doi.org/10.5902/1984686X37968

professores que concordaram em participar do estudo preencheram 0 Termo de Consentimento Livre e Esclarecido (TCLE).

\section{Instrumentos}

\section{Instrumento 1: Roteiro de Entrevista Semiestruturado}

Foi utilizado como instrumento de coleta de dados um roteiro para entrevista semiestruturada, inicialmente com 11 questões abertas. Após passar por quatro juízes, este roteiro passou por alterações e ajustes. Implementadas todas as adaptações necessárias chegou-se a uma versão final com 31 perguntas, com a objetivo de identificar as mediações pedagógicas dos professores direcionadas ao aluno com deficiência e necessidade complexa de comunicação.

\section{Instrumento 2: protocolo de Habilidades Comunicativas para Alunos não Falantes}

O segundo instrumento utilizado foi o "Protocolo para Identificação de habilidades comunicativas no contexto escolar", elaborado por De Paula (2007), em versão atualizada por De Paula, Manzini e Deliberato (2015) (Partes I e II) para apoiar e tornar mais fácil identificar a percepção dos professores quanto às suas mediações direcionadas aos alunos com deficiência e necessidade complexa de comunicação.

O protocolo apresenta-se em cinco seções, sendo uma seção de identificação das habilidades comunicativas do aluno e as outras de auxílio ao processo de avaliação dessas habilidades. Desta forma, o protocolo se apresenta dividido nas seguintes seções: 1) Identificação; 2) Principal; 3) Características da Personalidade do Aluno 1; 4) Rotina e Centros de Interesse; e 5) Profissionais.

De Paula, Manzini e Deliberato (2015) enfatizaram que a elaboração do protocolo motivou- se pela escassez de instrumentos avaliativos para o público de alunos com necessidades complexas de comunicação, e teve como objetivo possibilitar aos profissionais identificar e sistematizar tais habilidades.

\section{Procedimentos para coleta dos dados}

As coletas de dados ocorreram nas escolas em que cada participante pertencia. $O$ espaço físico que a equipe gestora definiu para que pudesse ocorrer o encontro entre pesquisador e professor variou de acordo com a disponibilidade das escolas. Desta forma, 
http://dx.doi.org/10.5902/1984686X37968

as coletas aconteceram entre sala de aula, biblioteca, sala dos professores ou sala da direção.

Os agendamentos foram realizados previamente, em dias e horários estabelecidos pelos professores. Respeitou-se a disponibilidade do professor em aula livre, ou seja, momento em que a turma estava em outra atividade.

Cinco dos professores entrevistados realizaram no mesmo dia as duas etapas necessárias para a coleta de dados e cinco solicitaram a realização da segunda etapa em um segundo encontro, de acordo com a sua disponibilidade de tempo.

\section{Procedimento de análise}

As entrevistas foram transcritas e analisadas. A posteriori foram estabelecidas as categorias dos conteúdos. Nas transcrições foram utilizados alguns ajustes, de acordo com as normas da ABNT e as contribuições de formas de transcrição de Marcuschi (1986). Por meio da análise das unidades temáticas, segundo Bardin (2004), foi possível estabelecer a posteriori temas e subtemas.

Os Temas e Subtemas foram enviados para avaliação de dois juízes da área, com o objetivo de identificar a representatividade, como proposto por Carvalho (1996). Foram selecionados trechos das falas dos professores, a fim de ilustrar os temas e os subtemas estabelecidos. Foram analisados 94 trechos. O nível de concordância reportou-se à comparação dos dados totais, analisados pela pesquisadora $(P)$ com o juiz $A(P-A)$; pesquisadora $(P)$ com o juiz $B(P-B)$; e entre os dados dos juízes $(A-B)$. $O$ índice de concordância entre os juízes: P-A; P-B; A-B; obtido foi superior a 70\%, ou seja, satisfatório para representar a concordância entre os juízes. Os resultados alcançaram índice mínimo de $82 \%$; e máximo de $96 \%$.

Para a construção deste artigo considerou-se a análise e a discussão de apenas um subtema incluso na subdivisão temática Mediação do Professor, que faz parte do tema Rotina Pedagógica da Sala de Aula, definido por todo relato do professor que descreveu a organização e a realização em etapas de seu planejamento em relação ao currículo e ao currículo adaptado (MARÍLIA/SP, 2016) estabelecido para cada série por meio de atividades e tarefas estabelecidas na sala de aula. 


\section{Resultados e discussões ${ }^{1}$}

Identificou-se, a partir da tabulação dos dados coletados com o Instrumento 1, que os professores participantes deste estudo possuíam tempo de atuação com variação entre 3 meses e 19 anos. Apenas um dos participantes não apresentava formação inicial em Pedagogia. Entre os participantes, três relataram experiência anterior com aluno com deficiência e necessidade complexa de comunicação.

Em sua dissertação de mestrado Rigoletti (2018) pontuou que as mediações pedagógicas podem apresentar diferentes subdivisões, deste modo a autora estabeleceu a primeira como: Física, ou seja, mediação com ajuda física ao aluno com deficiência e necessidade complexa de comunicação para realização de alguma atividade ou tarefa na rotina pedagógica da sala de aula.

A segunda subdivisão de mediação direcionada ao aluno com necessidade complexa de comunicação pontuada pela autora, diz sobre a ajuda do professor de caráter Verbal (vocal ou não vocal) e associada a um Modelo como meio de favorecer o aluno em situações de ensino.

A autora pontuou a terceira subdivisão de mediação em: auxílio Verbal (vocal ou não vocal) associado ao uso de Sistemas de CSA, utilizados na mediação com o aluno na atividade e na tarefa pedagógica, como promotores da participação na rotina pedagógica.

Por fim, elencou como a subdivisão Verbal baseada em código linguístico estruturado pode auxiliar o aluno com deficiência na atividade de sala de aula ou na sua comunicação.

Para maior clareza das subdivisões do subtema Mediação Pedagógica, veja-se a Tabela 1.

Tabela 1 - Subtemas

\begin{tabular}{l|l}
\hline Subtema & Subdivisões \\
\hline \multirow{3}{*}{ Mediação pedagógica } & Física \\
\cline { 2 - 2 } & Verbal e modelo \\
& Verbal e uso dos sistemas de CSA \\
\hline & Verbal \\
\hline
\end{tabular}

Fonte: Elaborada pela autora (2019). 
http://dx.doi.org/10.5902/1984686X37968

Rigoletti (2018) considerou quanto a mediação realizada com caráter verbal e não verbal, vocal e não vocal as definições de Millikin (1996).

Segundo Millikin (1996) as habilidades da linguagem expressiva do indivíduo apresentam diferentes características, tais como: verbal e não verbal, vocal e não vocal, de tal forma que:

Verbal: modalidade expressiva que apresenta código linguístico estruturado. Exemplo: a fala.

Não Verbal: modalidade expressiva que apresenta ausência de um código linguístico estruturado. Exemplo: gritos.

Vocal: modalidade expressiva que apresenta produção de som. Exemplo: gargalhadas.

Não vocal: modalidade expressiva que apresenta ausência de produção de som. Exemplo: escrita.

A Tabela 2 (a seguir) exibe as definições dos subtemas Mediação Pedagógica.

Tabela 2 - Definições dos subtemas

\begin{tabular}{l|l}
\hline Subtema & Definições \\
\hline Física & $\begin{array}{l}\text { Relato sobre a mediação do professor com ajuda física } \\
\text { ao aluno com deficiência e necessidade complexa de } \\
\text { comunicação para realização de alguma atividade ou } \\
\text { tarefa na rotina pedagógica da sala de aula. }\end{array}$ \\
\hline Verbal e modelo & $\begin{array}{l}\text { Relato sobre a realização de uma mediação com o aluno } \\
\text { com deficiência e necessidade complexa de } \\
\text { comunicação por meio de uma ajuda verbal e com } \\
\text { auxílio de um modelo. }\end{array}$ \\
\hline Verbal e uso dos sistemas de CSA & $\begin{array}{l}\text { Relato sobre sua mediação com o aluno com deficiência } \\
\text { e necessidade complexa de comunicação com } \\
\text { associação de instrução verbal, e o uso de sistemas de } \\
\text { CSA na atividade e tarefa pedagógica }\end{array}$ \\
\hline Verbal & $\begin{array}{l}\text { Relato de auxílio ao aluno com deficiência e } \\
\text { necessidade complexa de comunicação na atividade de } \\
\text { sala de aula ou na sua comunicação. }\end{array}$ \\
\hline
\end{tabular}

Fonte: Elaborado pela autora (2019).

Durante as entrevistas deste estudo, os professores relataram a necessidade de mediação pedagógica mais pontual com os alunos com deficiência e necessidade complexa de comunicação. Os relatos dos professores (P1) e (P5) nos permitiram uma observação quanto à mediação Física: 
http://dx.doi.org/10.5902/1984686X37968

Então, quando ele vai pintar a gente pega na mão dele, mas quando ele tem que mexer com tinta ele gosta. E é assim, eu proporciono, como os outros estão fazendo, mesmo que eu tenho que pegar a mão e fazer... assim, é praticamente com ele! Mas ele tem o contato, ele gosta de mexer com as coisas. (P1)

Muita coisa tem que ser com auxílio mesmo, auxiliar na mão e ir (...). (P5)

A mediação entre professor e aluno é uma ação importante para o desenvolvimento do ensino e aprendizagem de pessoas com deficiência, em que podem demonstrar, em situações de aprendizagem mediada, habilidades cognitivas e capacidade de generalizar o conhecimento e aplicá-los em outra situação (FEUERSTEIN, 1997).

Os professores destacaram a necessidade de mediação física para que os alunos realizassem as atividades propostas. Caso contrário, muito se dificultaria o acesso e a participação dos alunos. Poker et al. (2013, p.22) destacaram frente a obrigatoriedades da escola que $(. .$.$) deve se adequar e se preparar para atender às condições de seu alunado".$

Em situação de rotina pedagógica a mediação do professor por meio de um código linguístico estabelecido (verbal) faz-se predominante e, ao considerar as especificidades de seus alunos, revela-se a importância do modelo baseado na ação verbal, conforme destacaram os relatos dos professores (P5), (P2) e (P7):

No dia do bolo de aniversário, eu fiz um bolo horrível que eu desenho super mal, mas eu coloquei umas bolinhas em cima. Falei: "Ai, eu vou colocar uns docinhos aqui... porque esse bolo tá muito feio". E aí ela fez, ela pintou as bolinhas coloridas sabe? (P5)

Então ela não me aceitava. Daí eu falava com ela " vamos fazer?". ela "Não!". Eu nem terminava a frase e ela dizia que não, sabe? Então tudo foi mesmo uma construção. Então eu chegava mais cedo, eu comecei a chegar mais perto dela pra falar, sabe? Falar mais baixo, explicar mais. " vamos fazer assim agora?". Então agora ela me aceita mais. (P5)

A gente tinha uma atividade que ela tinha que colar (...), pra colar o palitinho, era a casinha do Chapeuzinho Vermelho, colar palitinho de fósforo no contorno (...) Eu falava assim com ela (...) olha dois palitinhos, colava dois palitinhos. (P2)

Ela emite corretamente o som, e frases ela repete inteirinha. Se você falar " faz isso", daí depois ela repete "faz isso ". E tem uma coisa [...] que eu não sei se ela tem percepção dela sobre ela mesma. (P7)

Silva e Deliberato (2003) discutiram as dificuldades e preocupações dos professores a respeito dos alunos com deficiência e com necessidade complexa de comunicação. Como se enfatizou, o professor (P5) identificou a necessidade de associar, à sua mediação verbal, o modelo para atender as especificidades do aluno na realização das atividades/tarefas escolares e favorecer o processo de interação. Quando o aluno com deficiência e 
http://dx.doi.org/10.5902/1984686X37968

necessidade complexa de comunicação participa de mediações inadequadas às suas necessidades, as alterações na linguagem podem Ihe causar prejuízos em um ambiente escolar onde a maioria de seus participantes tem o domínio das regras de comunicação.

Desta forma, o uso adequado do modelo, coadunado com a mediação verbal, garantiria melhor acesso dos alunos na rotina pedagógica. Ao considerar as discussões que Sobrinho e Medrado (2017) realizaram em estudo sobre as diversas formas que a comunicação pode assumir, tais como fala, gesto, atenção compartilhada, símbolos, dentre outros, o uso delas em contexto escolar favorece a mediação e a interação professor-aluno.

No relato do professor (P9) pode-se perceber a relevância de uma mediação verbal associada com o modelo:

Nós falamos a palavra, nós falamos devagar, damos esse auxílio fonético pra ela, então bola, bo bo bo que letra que vem que vai, qual é a letrinha, então ela consegue falar do jeitinho dela e pegar essa letrinha, com auxílio ela consegue fazer esse trabalho de forma individual, com autonomia ela não consegue, entendeu? (P9)

Este trecho transcrito do relato do professor (P9) possibilitou analisar uma associação em sua mediação, apoiada na comunicação e interação. Se a capacidade de representação simbólica se mostra essencial para a comunicação, representada pela linguagem gestual, oral ou gráfica, a comunicação interpessoal favorece o desenvolvimento da cognição e da linguagem (NUNES; SCHIRMER, 2017). Ao continuar a análise de trechos expressos pelo professor (P9) observou-se que a mediação verbal e o uso do modelo do mediador tinham destaque:

\footnotetext{
Nós sentamos em roda e falamos sobre o nosso final de semana, então "o que você fez no final de semana", e como ela não fala nós temos um caderno que a mamãe e o papai mandam que constroem com ela em casa, então eles trazem, relembro com ela "olha o que você fez", " o que está escrito aqui", "ah, então eu fui no aniversário do amigo", "vamos escrever", "eu, primeiro eu", "Fui, Fui", "no aniversário", então aos pouquinhos vamos dando este auxílio para ela, sozinha ela não faz isso (P9).
}

O ensino da habilidade de ler e escrever apoia-se em sua maioria na oralidade para escrita alfabética (DELIBERATO, 2009; SMITH, 2017). Quando os professores se deparam com alunos sem possibilidade de utilizar a linguagem falada como instrumento de comunicação podem surgir angústias e sensação de incapacidade.

Quanto à expressão do professor (P9) sobre a organização dos alunos em rodas de conversa, que exploram e desenvolvem a linguagem, Nunes e Schirmer (2017) apregoaram que "rodas de conversa", proporcionadas pelo professor com o intuito de desenvolvimento 
http://dx.doi.org/10.5902/1984686X37968

da linguagem e da socialização, mostram-se cada vez menos comuns em cursos do ensino fundamental.

A mediação do professor (P9) retratou a diversidade em situações de ensino com a aluna para lidar com suas especificidades educacionais a fim de que, segundo Poker et al. (2013, p.15) "seja capaz de identificar e satisfazer as necessidades de aprendizagem".

Durante as discussões dos relatos do professor (P9) foi possível identificar, em sua rotina pedagógica, mediações direcionadas à aluna, com a preocupação de desenvolver sua fala. Para isto, foi utilizada não somente a mediação verbal como também o modelo correto, que busca favorecer a habilidade expressiva verbal (fala) da aluna. Segue relato:

\begin{abstract}
Ela fala suco na hora do lanche, ela fala co co, então eu falo, "você quer suco, é suco que você quer", daí ela fala co co, nós trabalhamos a palavra falada de forma correta, que foi a orientação da fono, falar de maneira correta pra ver se ela repete, dar esse tempo pra ela, mas e as palavras que ela não está falando, e a palavra, que ela, nós não estamos entendendo, fica sem entender? (P9)
\end{abstract}

Segundo Deliberato (2017), o diálogo constante na rotina pedagógica favorece a aquisição de novos vocabulários, que permitem ampliar sua linguagem e atuar nos processos de interação e comunicação de forma efetiva.

Quanto à discussão da mediação do professor ser apoiada pelo uso de CSA, percebese que somente a mediação verbal não é suficiente para o aluno com deficiência e necessidade complexa de comunicação. Destacou o professor (P1):

(...) aquela historinha, então eu mostrei imagem, né? (...) quando eu mostrei a raposinha com fome e atribuí sentido, aí ele conseguiu responder: "Olha, ela tá com frio ou ela tá com fome?" Aí eu lia novamente o texto: "Como que ela tá? Tá com fome ou tá com frio?" (P1).

Em ambiente escolar, Manzini e Deliberato (2004) pontuaram que o uso de material que apoia a comunicação possibilita, além da interação do aluno com o professor, com os colegas e com os demais funcionários da escola, sua participação em estratégias do planejamento curricular e das demais atividades da escola.

Nunes e Schirmer (2017) evidenciaram que os recursos visuais, representados pelas imagens, auxiliam a compreensão do aluno e também a expressão de seu pensamento na realização das tarefas/atividades com excelência. No relato seguinte o professor (P1) destacou que, na mediação verbal com o aluno com deficiência e necessidade complexa de comunicação, utiliza os sistemas de CSA:

Às vezes assim para pegar alguma coisa... então alguma criança está conversando e diz assim: "você quer tal coisa"? Algum objeto sempre estão 
http://dx.doi.org/10.5902/1984686X37968

auxiliando... mas para entender, para que ele entenda, a gente já está fazendo até o uso de imagem... eu mesma estou fazendo, então digo: "Olha, mostra para ele. Qual que ele quer?" (P1).

Quanto às possibilidades explícitas nas mediações dos professores e ao uso de sistemas de CSA, Bersch e Sartoreto (2017) reconheceram que ainda há muito para avançar neste aspecto, pois normalmente as mediações se resumem a pensar em pranchas, centradas especificamente na habilidade do aluno se comunicar, deixando de lado as possibilidades que devem ser oportunizadas aos parceiros de comunicação.

Embora no próximo relato o professor (P4) tenha anunciado fazer uso dos sistemas de CSA na rotina pedagógica como maneira de sua aluna com necessidade complexa de comunicação expressar opinião, revelou que a mesma não inicia uma situação espontânea com o interlocutor. Veja:

Eu trabalho textos, histórias e mostro imagens de personagens daquele texto e vou contando e assim ela vai interagindo e se expõe um pouquinho, coloca um pouco da opinião dela, mas assim, chegar e dizer "minha mãe me deu isso", isso não (P4).

Apesar de identificar no relato do professor o cuidado de realizar mediação verbal com o apoio de sistemas de CSA, é fundamental que sejam priorizados em sua rotina pedagógica o desenvolvimento e a ampliação de suas intenções comunicativas em diferentes situações.

Sistemas de CSA promovem relações interpessoais de socialização e afetividade, ao possibilitar momentos prazerosos de atividades. Sendo assim, o beneficiado assume papel ativo e com aumento da probabilidade de expor seu potencial (FABRI; SELLA,2017).

Além dos sistemas de CSA representarem um meio alternativo de comunicação para o aluno com necessidade complexa de comunicação participar das diversas práticas pedagógicas e sociais, apresenta-se também como possibilidade de comunicar suas ideias em diferentes situações e tornar mais amplas suas vivências, de forma a resultar na construção do conhecimento de natureza conceitual, colaborando com o processo de ensino e aprendizagem (MASSARO; DELIBERATO, 2013).

O relato do professor (P7) nos permitiu identificar que percebeu a necessidade dos sistemas de CSA em sua rotina pedagógica:

Acho que ela precisa da Comunicação Alternativa em algum momento. Acho que ela precisaria (P7). 
http://dx.doi.org/10.5902/1984686X37968

Elaborar, implementar e fazer o uso de recursos de CSA em contexto escolar beneficia os usuários e seus parceiros de comunicação em diferentes contextos (BERSCH; SARTORETTO, 2017). A consideração no relato do professor (P7) nos permite discutir o quanto as apropriações de mediações associadas a alternativas de comunicação trazem mais possibilidades para o aluno com deficiência e necessidade complexa de comunicação. Tais associações permitem que a criança transite com orientação ou em parceria com outras pessoas mais capazes e evolua para o que é capaz de fazer sozinha (ALENCAR, 2002).

Quando usado em benefício do desenvolvimento, o uso do sistema de CSA aliado à mediação verbal torna os alunos com necessidade complexa de comunicação mais estimulados a participar das atividades e a trocar ideias em situações de ensino e aprendizagem. Nas mediações direcionadas à aprendizagem destes alunos é necessário um olhar destemido do professor, para que possa buscar avanços no desenvolvimento escolar e comunicativo.

O subtema Mediação Verbal explícito na Tabela 2 primou por discutir relatos emitidos pelos professores em situação de mediação baseada em código linguístico estruturado, que possa auxiliar o aluno com deficiência na atividade de sala de aula ou na sua comunicação. Seguem exemplos de mediação verbal explícitos nos relatos dos professores (P6) e (P9):

Agora se eu sentar do lado dele e dizer faz o M, e ele faz. Faz o A, aí ele faz. Faz o T, aí ele faz errado, mas não é pra este lado, olha de novo, como que é o T? Ele olha, aí ele apaga e arruma. Só que assim, se não tiver uma pessoa ali do lado ele não [...] então é assim, quando são coisas muito grandes, muito compridas, ele não consegue mesmo. Agora quando é coisa curta, como o nome dele ou alguma outra coisa ele consegue. (P6)

Ele participa quando é atividade que eu digo "Olha, faz isso". Ele faz. Agora, quando é no coletivo... ele não está nem ai. (P6)

Ela não tem essa autonomia de fazer as atividades sozinhas, ela não consegue, tem que alguém ir explicando pra ela individualmente, falando pausadamente, devagar, e ir fazendo essas adaptações nas atividades, seja ela na linguagem oral e escrita, na matemática, ciências, enfim. (P9)

Uma das formas identificadas nos relatos dos professores e presente em contexto escolar é a mediação verbal expressa por meio de um código linguístico estabelecido. Promover situações de busca de conhecimento permite experiências fecundas na condição do aluno com necessidade complexa de comunicação. A lente adequada para se enxergar a aprendizagem na escola é a da mediação. É a compreensão de que a realidade concreta 
http://dx.doi.org/10.5902/1984686X37968

passa por várias intersecções, experiências, mediações que fazem dela o que é (MAGALHÃES; MENDONÇA,2016).

É comum identificar, no relato dos professores quanto à rotina pedagógica da sala de aula, suas percepções quanto à dificuldade de lidar com situações de mediação (seja ela qual for) com o aluno com deficiência e necessidade complexa de comunicação, como os relatos dos professores (P1), (P2) e (P3) elucidaram:

\footnotetext{
Não sei te dizer, é tentativa e erro na verdade assim, a gente tenta, algumas coisas dão certo, outras não, assim, a gente vai meio tateando, meio que no escuro, né. (P2)

Nossa, precisa melhorar um monte de coisa, desde recurso, atendimento de profissional adequado, que eu consiga estabelecer uma relação com ela.... (P2)

Agora assim o que precisa melhorar mesmo é essa questão vamos supor, quando eu tenho que ficar com ele, é um momento que eu preciso me dedicar. Então se eu conseguisse aproximar mais os demais alunos para que eles também participassem e não ficasse uma coisa estanque... Olha, agora é o momento do amigo. Lógico que eu vou ter que fazer coisas com ele sim, que é eu e ele ali. (P1)

É assim, tem a questão da comunicação, muito... eu fico em dúvida às vezes se ele está aprendendo de acordo com o que é desejado. Mas eu creio que ele está avançando. É uma dúvida mais minha mesmo. (P3)
}

De acordo com as falas dos professores, percebem-se tateios em suas mediações, permeados por discursos que ficam muitas vezes sem resposta, devido à condição de comunicação apresentada pelo aluno com fala inexistente ou insuficiente. De acordo com Feuerstein (1997) todos os alunos são capazes de aprender, porém a aprendizagem só acontece quando a mediação Ihes trouxer conhecimentos significativos e singulares, de acordo com as possibilidades de cada um.

De acordo com dados deste estudo, ficou evidente que ainda é necessário implementar mediações pedagógicas na rotina escolar que contemplem o processo educacional de tais alunos.

Entre as ações na rotina escolar que poderiam favorecer o aluno com deficiência e necessidade complexa de comunicação está a aprendizagem de novos conceitos e o domínio do professor em realizar uma avaliação que proporcionasse objetivos claros quanto ao trabalho com o aluno.

Destaca-se também a necessidade de planejamento, elaboração e implementação de uma rotina pedagógica direcionada aos alunos com deficiência e necessidade complexa de comunicação como favorecedora do desenvolvimento das atividades, no ensino e na aprendizagem de tais alunos. 
http://dx.doi.org/10.5902/1984686X37968

Os resultados desta pesquisa apontaram a necessidade da obrigatoriedade legal de ser oferecida formação inicial e continuada com conteúdos específicos que possam contemplar as diversas características dos alunos do ensino regular.

A garantia de participação e aprendizagem de todos os alunos na escola contribui para a construção de uma nova cultura de valorização das diferenças e da igualdade de direitos. Um aluno com necessidade complexa de comunicação sem a possibilidade de expressar seus desejos, não estará atendido em suas necessidades. Os professores precisam compreender que existem possibilidades alternativas de se estabelecer uma comunicação que permita a esses alunos condições reais de acesso e permanência na escola, equiparando oportunidades e oferecendo uma educação de qualidade para todos.

Esta ideia nos permite identificar que a Educação Especial ainda busca a melhor forma de elaborar, implementar e promover as mediações pedagógicas de modo que possa garantir a participação plena de todos na rotina pedagógica. Como pontuaram Marinho e Omote (2017) a diversidade do público tem provocado novos olhares e discussões quanto à construção e consolidação da inclusão escolar.

\section{Conclusão}

Buscou-se neste artigo identificar as mediações pedagógicas direcionadas ao aluno com deficiência e necessidade complexa de comunicação. A relevância dessa temática consiste em contribuir não somente com as mediações realizadas pelo professor, mas de forma que suas percepções promovam condições de ações na rotina escolar com objetivos claros no desenvolvimento de novas habilidades acadêmicas dos alunos com deficiência e necessidade complexa de comunicação.

A inabilidade do professor em avaliar o real desenvolvimento de um aluno com deficiência e necessidade complexa de comunicação dificulta direcionar sua mediação pedagógica e contribuir para as novas aprendizagens.

A formação inicial e continuada dos professores entrevistados aponta a necessidade de se oferecerem conteúdos específicos que contemplem as diversas características dos alunos do ensino regular e forneçam aos educadores condição de atuação, de modo que possam ser competentes em modificar o conhecimento dos alunos.

Outro dado importante identificado pelo presente estudo é a falta de planejamento dos professores para a elaboração e implementação de recursos, sistemas e estratégias 
adequadas na rotina pedagógica direcionada aos alunos com deficiência e necessidade complexa de comunicação.

Os dados do presente estudo evidenciaram que, de acordo com as percepções dos professores, fica claro que a CSA é um dos caminhos que facilitaria as intenções comunicativas do aluno e traria benefícios para as mediações pedagógicas, contribuindo com o desenvolvimento de habilidades acadêmicas do aluno.

Os resultados dessa investigação revelam demandas por outros estudos, de natureza interventiva. Ou seja, é de grande valia a promoção de pesquisas que possam promover o conhecimento e a construção de novas mediações pedagógicas por meio da reflexão e ação do professor do ensino regular.

Por fim, considerou-se como limitação para realização deste estudo a desistência de um participante da pesquisa na trajetória metodológica com a justificativa de que sua equipe diretiva promove toda a formação e capacitação de seus professores sem se fazer necessária as contribuições desse projeto.

\section{Referências}

ALENCAR, Gizeli Aparecida Ribeiro de. 0 direito de comunicar, por que não? Comunicação Alternativa aplicada a portadores de necessidades educativas especiais no contexto de sala de aula. 2002. Disponível em:

25reuniao.anped.org.br/gizeliribeiroalencart15.rtf. Acesso em: 18 mar. 2020.

American Speech-Language-Hearing Association (ASHA). Competencies for speechlanguage pathologists providing services in augmentative communication. ASHA, v.3, p.07-10,1989.

BARDIN, Laurence. Análise de Conteúdo. 3. ed. São Paulo: Edições 70, 2004.

BERSCH, Rita; SARTORETTO, Maria Lúcia. Formação de professores para a promoção e vivência da Comunicação alternativa no contexto escolar. In: DELIBERATO, Débora; NUNES, Débora Regina de Paula Nunes; GONÇALVES, Maria de Jesus (Org.). Trilhando juntos a comunicação alternativa. Marília: ABPEE, 2017, p. 197204.

BRASIL. Lei Brasileira de Inclusão da pessoa com Deficiência (Estatuto da Pessoa com Deficiência). 06 de junho de 2015. Disponível em:

http://www.planalto.gov.br/ccivil_03/_Ato2015-2018/2015/Lei/L13146.htm. Acesso em: 18 mar. 2020.

BULGRAEN, Vanessa Cristina. O papel do professor e sua mediação nos processos de elaboração do conhecimento. Revista Conteúdo, Capivari, v.1, n.4, p. 30-38, ago/dez 2010. 
CARDOSO, Leila Aparecida Assolari; TOSCANO, Carlos. A mediação pedagógica na sala de aula: o papel do professor na construção do conhecimento. Anais do $X$ Congresso Nacional de Educação. Educere. Universidade Católica do Paraná-PUCPR, 2011. Disponível em: https://educere.bruc.com.br/CD2011/pdf/5829_2776.pdf. Acesso em: 18 mar. 2020.

CARNEIRO, Maria Sylvia Cardoso. A deficiência mental como produção social: de Itard à abordagem histórico-cultural. In: BAPTISTA, Claúdio Roberto (Org.). Inclusão e escolarização. Porto Alegre: Mediação, 2006, p.137-152.

CARVALHO, Anna Maria Pessoa de. O uso do vídeo na tomada de dados: pesquisando o desenvolvimento do ensino em sala de aula. Pro-Posições, Campinas, v.7, n.1, 1996, p. 5-13.

DE PAULA, Raquel. Desenvolvimento de um protocolo para avaliação de habilidades comunicativas de alunos não-falantes em ambiente escolar. 109f. Dissertação (Mestrado em Educação) - Faculdade de Filosofia e Ciências. Universidade Estadual Paulista, Marília, 2007.

DE PAULA, Raquel; MANZINI, Eduardo José; DELIBERATO, Débora. Protocolo para identificação de habilidades comunicativas no contexto escolar. In: DELIBERATO, Débora; MANZINI, Eduardo José. (Orgs). Instrumentos para avaliação de alunos com deficiência sem oralidade. São Carlos: Marquezine \& Manzini: ABPEE, 2015, p. 41-83.

DELIBERATO, Débora. Comunicação Alternativa na Educação Infantil: instrumentos para aquisição de competências do aluno com deficiência. In: DELIBERATO, Débora; NUNES, Débora Regina de Paula Nunes; GONÇALVES, Maria de Jesus (Org.). Trilhando juntos a Comunicação Alternativa. Marília: ABPEE, 2017, p. 77-95.

DELIBERATO, Débora. Comunicação Alternativa na escola: habilidades comunicativas e o ensino da leitura e escrita. In: DELIBERATO, Débora; GONÇALVES, Maria de Jesus; MACEDO, Elizeu de Coutinho (Orgs.). Comunicação alternativa: teoria, prática, tecnologias e pesquisa. $1^{\circ}$ ed. São Paulo: Memnon Edições Científicas, 2009, v.1, p. 235243.

DUDAS, Tatiana Lanzarotto. A Comunicação Alternativa como potencializadora da inclusão escolar? In: PASSERINO, Liliana Maria et al. (Org). Comunicar para incluir. Porto Alegre: CRBF, 2013. p. 83-97.

DONATI, Grace Cristina Ferreira. Quais caminhos trilha a Comunicação Suplementar e/ou Alternativa na clínica fonoaudiológica da infância e da adolescência? In: DELIBERATO, Débora; NUNES, Débora Regina de Paula Nunes; GONÇALVES, Maria de Jesus (Org). Trilhando juntos a comunicação alternativa. Marília: ABPEE, 2017, p. 289-302.

FABRI, Marisa Hirata; SELLA, Karina Rizzardo A Comunicação Suplementar e Alternativa na clínica com adultos e idosos: desafios e saberes na busca da funcionalidade da comunicação. In: DELIBERATO, Débora; NUNES, Débora Regina de Paula Nunes; GONÇALVES, Maria de Jesus (Org.).Trilhando juntos a comunicação alternativa. Marília: ABPEE, 2017, p. 319-335. 
FEUERSTEIN, Reuven. (1997). Teoria de la modificabilidad cognitiva estructural. In R. Feuerstein. Es modificable la inteligencia? Madrid: Editora Bruno, 1997, p. 11-23.

FEUERSTEIN, Reuven, KLEIN, Pnina S., TANNENBAUM, Abraham J. (1994). Mediated learning experience (MLE): theoretical, psychosocial and learning implications. London: Freund, 1994.

FIORIN, José Luiz. Linguagem e ideologia. São Paulo: Ática, 1998.

GASPARIN, João Luiz. Uma didática para a pedagogia histórico-crítica. 4. ed. Campinas, SP: Autores Associados, 2007, p. 113-115.

GUERREIRO, Elaine Maria Bessa Rebello. A acessibilidade e a educação: um direito constitucional como base para um direito social da pessoa com deficiência. Santa Maria, RS: Revista Educação Especial, v. 25, n. 43, p. 217-232, maio/ago 2012. Disponível em https://periodicos.ufsm.br/educacaoespecial/article/view/4415/3816. Acesso: 18 mar. 2020.

HERCULIANI, Cristóvam Emílio; DELIBERATO, Débora. O uso do software PowerPoint como recurso de comunicação alternativa. In: Jogos e recursos para comunicação e ensino na educação especial. Ed. Marília: ABPEE, 2010, p. 161-175.

LIBÂNEO, José Carlos. Didática. São Paulo: Cortez, 1994. Coleção Magistério $2^{\circ}$ grau. Série Formação do Professor.

MAGALHÃES, Luciana Oliveira Rocha; MENDONÇA, Suelene Regina Donola. Ação interdisciplinar e transformação da realidade: construção de sonhos e práticas inclusivas em sala de aula. Santa Maria: Revista Educação Especial, v. 29, n. 54, p. 161-174, jan/abr 2016. Disponível em:

https://periodicos.ufsm.br/educacaoespecial/article/view/17865/pdf. Acesso: 25 jan. 2018.

MANZINI, Eduardo José; DELIBERATO, Débora. Portal de ajudas técnicas para educação, capacitação e recreação da pessoa com deficiência física: recursos para comunicação alternativa. Secretaria de Educação Especial. Brasília, DF: ABPEEMEC/SEESP, 2004. 52p.

MANZINI, Eduardo José; DELIBERATO, Débora. Portal de ajudas técnicas para educação: equipamento e material pedagógico para educação, capacitação e recreação da pessoa com deficiência física: recursos pedagógicos adaptados II /Secretaria de Educação Especial - Brasília: ABPEE-MEC: SEESP, 2007. Fascículo 4. $72 p$.

MARCUSCHI, Luiz Antônio. A análise da conversação. São Paulo: Ática, 1986. 96p. (Série Princípios).

MARÍLIA (SP). Secretaria Municipal de Educação. Centro Escola Municipal de Atendimento Educacional Especializado. "Profa. Yone Gonçalves". Referencial de Adequação Curricular Individualizado. Ensino Fundamental. Secretaria Municipal de Educação. Marília: SME, 2016. 45p. 
MARINHO, Carla Cristina; OMOTE, Sadao. Concepções de futuros professores a respeito da Educação Inclusiva e Educação Especial. Revista Educação Especial, Santa Maria, v. 30, n. 59, p. 629-642, set/dez. 2017. Disponível em:

https://periodicos.ufsm.br/educacaoespecial/article/view/28085/pdf. Acesso em: 18 mar 2020.

MASSARO, Munique; DELIBERATO, Débora. O uso de sistema de Comunicação suplementar e alternativa na Educação Infantil: percepção do professor. Revista Educação Especial, Santa Maria, v.26, n. 46, p. 331-350, maio/ago. 2013. Disponível em: https://periodicos.ufsm.br/educacaoespecial/article/view/4821/pdf. Acesso em: 18/03/2020.

MELLO, Guiomar Namo de. Formação inicial de professores para a educação básica: uma (re)visão radical. Revista São Paulo em Perspectiva, São Paulo, vol.14, n.1, p. jan. /mar. 2000. Disponível em: http://www.scielo.br/scielo.php?script=sci_arttext\&pid=S010288392000000100012. Acesso em: 20 mar. 2020.

MILLIKIN, Cindy C. Symbol systems and vocabulary selection strategies. In: Glennen, S.L.; DeCoste, Denise C. Handbook of augmentative and alternative communication. San Diego, London: Singular Publishing Group, 1996. p. 97-148.

MONNERAT, Thereza; WALTER, Cátia Crivelenti de Figueiredo. A estimulação precoce e a Comunicação Alternativa para crianças com Transtorno do Espectro do autismo: Relatos de casos utilizando o PEC-S adaptado. In: DELIBERATO, Débora; NUNES, Débora Regina de Paula Nunes; GONÇALVES, Maria de Jesus (Orgs.) Trilhando juntos a comunicação alternativa. Marília: ABPEE, 2017, p. 257-272

MORESCHI, Cândice Lima; ALMEIDA, Maria Amelia. Práticas da fonoaudiologia educacional no contexto da Educação Inclusiva; Possibilidades e realidades quanto ao uso da Comunicação Alternativa. In: DELIBERATO, Débora; NUNES, Débora Regina de Paula Nunes; GONÇALVES, Maria de Jesus (Orgs.). Trilhando juntos a comunicação alternativa. Marília: ABPEE, 2017, p. 133-146.

NUNES, Leila Regina d' Oliveira de Paula; SCHIRMER, Carolina Rizzotto. Trilhando juntos a Comunicação Alternativa. In: DELIBERATO, Débora; NUNES, Débora Regina de Paula Nunes; GONÇALVES, Maria de Jesus (Orgs.). Trilhando juntos a comunicação alternativa. Marília: ABPEE, 2017, p. 63-74.

POKER, Rosimar Bortolini et al. Plano de desenvolvimento individual: Avaliação e prática pedagógica na sala de recursos multifuncional. In: POKER, Rosimar Bortolini; MARTINS, Sandra Eli Sartoreto de Oliveira; OLIVEIRA, Anna Augusta Sampaio; MILANEZ, Simone Ghedini Costa; GIROTO, Claudia Regina Mosca (Orgs.). Plano de desenvolvimento individual para o atendimento educacional especializado. São Paulo: Cultura Acadêmica; Marília: Oficina Universitária, 2013, p. 184.

REGANHAN, Walkiria Gonçalves. Recursos e estratégias para o ensino de alunos com deficiência: percepção de professores. 2006. Dissertação (Mestrado) - Faculdade de Filosofia e Ciências, Universidade Estadual Paulista, Marília -SP, 2006. 
REIS, Maria Cristina.et al. A implantação da rotina didática no primeiro ano do ensino fundamental. Anais do XV Encontro Latino Americano de Iniciação Científica, XI Encontro Latino-Americano de Pós-Graduação. V Encontro de Iniciação Científica Júnior. Universidade Vale da Paraíba ,2011. Disponível em: http://www.inicepg.univap.br/cd/INIC_2011/anais/arquivos/0147_1053_01.pdf.Acesso em: 18 mar 2020.

RIGOLETTI, Vanessa Calciolari. Habilidade comunicativa e rotina pedagógica de alunos com deficiência não falantes: relato de professoras. Dissertação (Mestrado em Educação). Marília: Faculdade de Filosofia e Ciências, Universidade Estadual Paulista, 2018, 146p.

SCHIRMER, Carolina Rizzotto. Compartilhando Experiências: ampliando a comunicação alternativa. Marília: ABPEE, 2011, p. 187.

SCHIRMER, Carolina Rizzotto. Formação Inicial e Continuada de Professores e Comunicação Alternativa: pontos importantes para vencer os desafios. In: PASSERINO, Liliana Maria et al./Org. Comunicar para incluir. Porto Alegre: CRBF, 2013. p. 266.

SILVA, Aldine; DELIBERATO, Débora. Comportamentos comunicativos utilizados por uma educadora na situação de alfabetização de um aluno com severo distúrbio na comunicação verbal. In: V Simpósio em Filosofia e Ciência - Trabalho e conhecimento: desafios e responsabilidades da ciência. Marília: Unesp Marília. Publicações, 2003. 1 CD-ROM.

SMITH, Martine. Building a solid foundation: linking language and literacy through aided communication. In: DELIBERATO, Débora; NUNES, Débora Regina de Paula Nunes; GONÇALVES, Maria de Jesus (Orgs.) Trilhando juntos a comunicação alternativa. Marília: ABPEE, 2017, p. 13-30.

SOBRINHO, Francisco de P. Nunes; MEDRADO, Cylene S. Comunicação aumentativa e alternativa no mundo do trabalho. In: DELIBERATO, Débora; NUNES, Débora Regina de Paula Nunes; GONÇALVES, Maria de Jesus (Orgs.). Trilhando juntos a comunicação alternativa. Marília: ABPEE, 2017, p. 205-218.

TRIVIÑOS, Augusto Nibaldo Silva. Introdução à pesquisa em ciências sociais: a pesquisa qualitativa em educação. São Paulo: Atlas, 1987, 176p.

\section{Notas}

\footnotetext{
${ }^{1}$ Este estudo analisou e discutiu as definições constantes do subtema Mediação do Professor, que faz parte do tema Rotina Pedagógica da Sala de Aula exposto na dissertação de mestrado de Rigoletti (2018).
} 


\section{Correspondência}

Vanessa Calciolari Rigoletti - Universidade Estadual Paulista Júlio de Mesquita Filho, Faculdade de Filosofia e Ciências - Campus de Marília, Departamento de Educação Especial, Rua Hygino Muzzi Filho, 737, Marília, São Paulo - Brasil.

CEP: $17525-900$

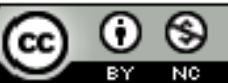

This work is licensed under a Creative Commons Attribution-NonCommercial 4.0 International (CC BY-NC 4.0) 